\title{
Tempo of Diversification of Global Amphibians: One-Constant Rate, One-Continuous Shift or Multiple-Discrete Shifts?
}

\author{
Youhua Chen ${ }^{1,2, *}$ \\ 'Department of Zoology, University of British Columbia, Vancouver, V6T 1Z4, Canada \\ ${ }^{2}$ Departmen of Renewable Resources, University of Alberta, Edmonton, T6G 2H1, Canada
}

\begin{abstract}
In this brief report, alternative time-varying diversification rate models were fitted onto the phylogeny of global amphibians by considering one-constant-rate (OCR), one-continuous-shift (OCS) and multiplediscrete-shifts (MDS) situations. The OCS diversification model was rejected by $\gamma$ statistic $(\gamma=-5.556, p<$ 0.001), implying the existence of shifting diversification rates for global amphibian phylogeny. Through model selection, MDS diversification model outperformed OCS and OCR models using "laser" package under R environment. Moreover, MDS models, implemented using another R package "MEDUSA", indicated that there were sixteen shifts over the internal nodes for amphibian phylogeny. Conclusively, both OCS and MDS models are recommended to compare so as to better quantify rate-shifting trends of species diversification. MDS diversification models should be preferential for large phylogenies using "MEDUSA" package in which any arbitrary numbers of shifts are allowed to model.
\end{abstract}

Keywords: adaptive radiation, rate variation, maximum likelihood, model selection and comparison

\section{INTRODUCTION}

Diversification rate shifting patterns over evolutionary history have been observed in many taxa (Barraclough and Vogler, 2002; Rabosky et al., 2007; Rabosky and Lovette, 2008a; Alfaro et al., 2009). According to the prediction of adaptive radiation (Schluter, 2000; Losos, 2010; Gillespie, 2013), diversification rates can vary over evolutionary time due to the limitations of ecological opportunities (Ricklefs, 2006; Rabosky, 2009; Harmon et al., 2010; Losos, 2010; Myers and Burbrink, 2012).

Diversification shifting pattern could be modeled in terms of a pattern with multiple-discrete shifts (MDS) (Alfaro et al., 2009; Antonelli and Sanmartín, 2011) or one-continuous shift (OCS) (Rabosky and Lovette, 2008a, 2008b) over the phylogeny. In comparison, a global one-constant-rate model (OCR) predicts that there are no shifting trends of diversification rates over the phylogenetic history, which might be used as a null model when investigating rate-shifting patterns of species diversification (Rabosky, 2007; Rabosky and Lo- vette, 2008a). MDS and OCR models can be implemented using "MEDUSA" package (Brown et al., 2013), while OCR and OCS models can be performed using "laser" package (Rabosky, 2007) under R environment (R Development Core Team, 2011). There are many systematic comparisons on using both $\mathrm{R}$ packages to model rate-changing patterns of species in previous literatures (Alfaro et al., 2009; Fordyce, 2010a; Rabosky et al., 2012). When it comes to the comparison of these two packages, "MEDUSA" package is much more flexible since it could allow multiple rate shifting patterns over the phylogeny (Brown et al., 2013). Thus, alternative hypotheses for testing rate shifting patterns of species diversification can be done easily using this package. In contrast, "laser" package is very limited because only three density-dependent models are implemented (Rabosky, 2006, 2007; Chen, 2013). However, as mentioned above, its advantage is to model the continuous rate shifting pattern.

Amphibian diversity has attracted much attention in recent years due to its high sensitivity to global climate change and habitat destruction (Wake, 1991, 2007). There are many

\footnotetext{
(c) This is an Open Access article distributed under the terms of the Creative Commons Attribution Non-Commercial License (http://creativecommons.org/ licenses/by-nc/3.0/) which permits unrestricted non-commercial use, distribution, and reproduction in any medium, provided the original work is properly cited.

pISSN 2234-6953 eISSN 2234-8190

*To whom correspondence should be addressed

Tel: 1-5877786218, Fax: 1-5877786218

E-mail: youhuach@gmail.com 
literatures contributing to understand global macroevolutionary and macroecological patterns of amphibians (Grenyer et al., 2006; Buckley and Jetz, 2007; Roelants et al., 2007; Wiens, 2007; Qian, 2009; Pyron and Wiens, 2011; Fritz and Rahbek, 2012). Moreover, diversification analysis of specific or overall amphibian clades has been found in some recent publications (Roelants et al., 2007; Wiens, 2007; Wollenberg et al., 2011; Zimkus et al., 2012). However, diversification rate analysis by comparing alternative rate-shifting models has not been performed on all the living amphibians yet seemingly in comparison to birds (Jetz et al., 2012) or other taxa (Rabosky et al., 2012).

In the present study, by comparing OCS, OCT and MDS models as described above, I evaluate the most appropriate evolutionary model for quantifying global amphibian temporal diversification patterns through model selection and comparison. I implement different models using both "MEDUSA" and "laser" packages.

For the present study, a full dated phylogenetic tree for global amphibians was obtained from the attached data sets in the "geiger" package (Harmon et al., 2008) under R environment (R Development Core Team, 2011), which was reconstructed on the basis of some previous studies (Roelants et al., 2007; Pyron and Wiens, 2011). More information about this tree file is available at URL: http://www.inside-r.org/ packages/cran/geiger/docs/amphibia.

The $\gamma$ statistic (Pybus and Harvey, 2000) was applied firstly to test whether diversification rates of amphibians would keep constant over evolutionary time scale. If the constantrate assumption was broken down, then time-varying diversification rate models should be employed to fit the phylogeny and the best one was chosen using Akaike Information Criteria (AIC) values.

OCS, OCT, and MDS models were fitted onto the amphibian phylogeny using "laser" package (Rabosky, 2007; Fordyce, 2010a). In specific, for OCS models, four models were implemented: DDX, DDL, SPVAR and EXVAR. DX and DDL fit exponential and logistic variants of the density-dependent speciation rate model respectively (Rabosky, 2006, 2007). SPVAR model is a model with an exponentially declining speciation rate through time and constant extinction, while EXVAR is a model with exponentially increasing extinction and constant speciation (Rabosky, 2006, 2007). For MDS models, the two-rate model (coded as "twoRate") is computed in "laser" package. MDS models with multiple discrete rates were implemented using "MEDUSA" package (Brown et al., 2013). The best number of discrete rate shifts in MDS model was selected through a stepwise AIC procedure (Brown et al., 2013).

When there was no rate shift in the species phylogeny, MDS model was equivalent to OCT model when using "MEDUSA"
Table 1. Model comparison and selection of different rate-varying models and the constant-rate model for the diversification rates of global amphibians using "laser" package

\begin{tabular}{llc}
\hline Model & Likelihood & AIC \\
\hline DDX & $8,427.032$ & $-16,850.06$ \\
DDL & $8,415.036$ & $-16,826.07$ \\
SPVAR & $8,390.294$ & $-16,774.59$ \\
EXVAR & $8,410.43$ & $-16,814.86$ \\
OCR & $8,411.812$ & $-16,819.62$ \\
twoRate & $\mathbf{8 , 5 0 5 . 2 2 9}$ & $\mathbf{- 1 7 , 0 0 4 . 4 6}$ \\
\hline
\end{tabular}

The best model is marked in boldface. AIC, Akaike Information Criteria.

package. In other words, MDS models nesetd OCT model in "MEDUSA" package. Besides, since OCT is a constant birth-death model, and therefore can be also estimated using the function "birthdeath" in the classical R phylogenetic package "ape" (Paradis et al., 2004).

\section{RESULTS}

The $\gamma$ statistic rejected the null model which stated that there was a globally constant diversification rate of amphibians over the evolutionary time $(\gamma=-5.556, \mathrm{p}<0.001)$. As a consequence, rate-shifting models can be applied to the phylogeny of global amphibians with reasonable grounds.

Throughout the comparison of AIC values for different rateshifting models implemented using "laser" package (Table 1), it was found that twoRate discrete model was the best one to characterize diversification rates of amphibians over the phylogeny in comparison to other OCS models. Furthermore, for the MDS models implemented using "MEDUSA" package, it was identified that there were sixteen shifts over different clades in the phylogeny (Fig. 1), further supporting the MDS model.

\section{DISCUSSION}

OCS diversification rate models have been applied and examined by a variety of species assemblages (Rabosky, 2006, 2009; Phillimore and Price, 2008; Rabosky and Lovette, 2008a). MDS models are also growingly applied in many recent studies (Alfaro et al., 2009; Santini et al., 2009; Pyron and Burbrink, 2012; Rabosky et al., 2012; Brown et al., 2013) given its high flexibility on modeling rate shifting patterns and identifying rate-changing lineages using stepwise AIC procedure (Alfaro et al., 2009). For global amphibians, it was found that there were sixteen shifts of the diversification rates in internal nodes over the evolutionary time, suggesting that 


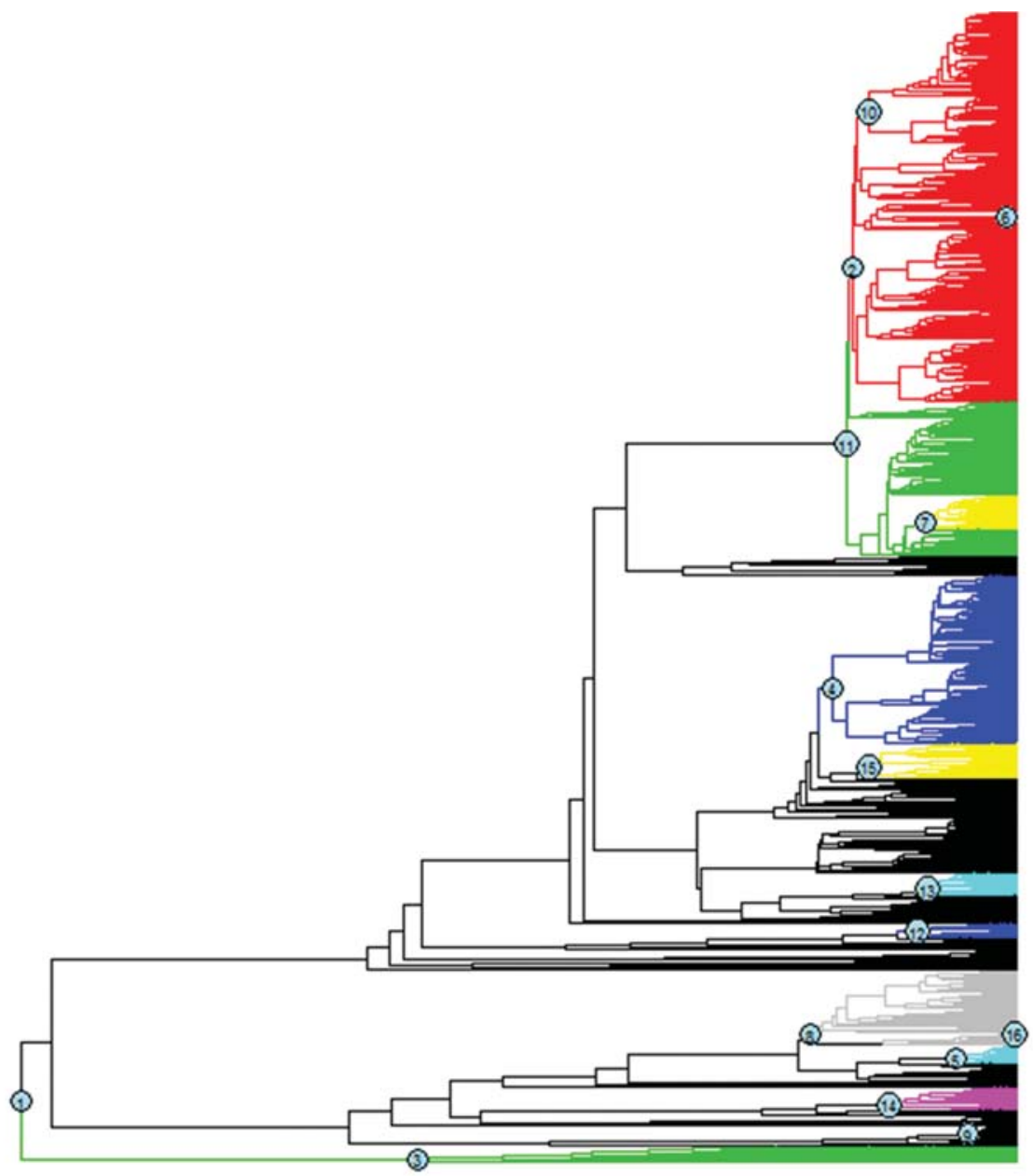

Fig. 1. Sixteen shifting events of diversification rates identified in the internal nodes for the phylogeny of global amphibians using "MEDUSA" package.

diversification rates of global amphibians follow MDS models.

"MEDUSA" package is the preferential choice in the analysis of time-varying diversification of species given the fact that multiple shifts of diversification rates are widely observed across different taxa (Jetz et al., 2012; Rabosky et al., 2012) and the rates after shifts can be either accelerated or reduced (Fordyce, 2010b; Jetz et al., 2012). However, "laser" package should be used when one wants to model time-declining OCS situation. But for large phylogenies, multiple shifts should be ubiquitous and thus MDS models may be one of the first choices to implement.

Sampling issue can be a prevailing problem limiting the implication of the present study. This is because phylogenetic trees usually can not cover all the external living species and may result into biases of the results (Chen, 2013). For my study, the amphibian phylogenetic tree used currently contains only 2,871 species, while global amphibians species has a number of over 7,000. Thus, no more than a half of the amphibian species can be represented and subsequently the robustness of the results should be verified in the future when more amphibian taxa are covered in the tree.

\section{ACKNOWLEDGMENTS}

This work was partially supported by a University of British Columbia graduate scholarship and China Scholarship Council.

\section{REFERENCES}

Alfaro ME, Santini F, Brock C, Alamillo H, Dornburg A, Rabosky DL, Carnevale G, Harmon LJ, 2009. Nine exceptional radiations plus high turnover explain species diversity in 
jawed vertebrates. Proceedings of the National Academy of Sciences of the United States of America, 106:13410-13414.

Antonelli A, Sanmartín I, 2011. Mass extinction, gradual cooling, or rapid radiation? Reconstructing the spatiotemporal evolution of the ancient angiosperm genus Hedyosmum (Chloranthaceae) using empirical and simulated approaches. Systematic Biology, 60:596-615.

Barraclough TG, Vogler AP, 2002. Recent diversification rates in North American Tiger beetles estimated from a dated mtDNA phylogenetic tree. Molecular Biology and Evolution, 19:1706-1716.

Brown JW, FitzJohn RG, Alfaro ME, Harmon LJ, Eastman JM, 2013. MEDUSA: modeling evolutionary diversification using stepwise AIC. R Graphical Manual.

Buckley LB, Jetz W, 2007. Environmental and historical constraints on global patterns of amphibian richness. Proceedings of the Royal Society B: Biological Sciences, 274: 1167-1173.

Chen YH, 2013. A phylogenetic subclade analysis of range sizes of endemic woody seed plant species of China: trait conservatism, diversification rates and evolutionary models. Journal of Systematics and Evolution, 51:590-600.

Fordyce JA, 2010a. Host shifts and evolutionary radiations of butterflies. Proceedings of the Royal Society B: Biological Sciences, 277:3735-3743.

Fordyce JA, 2010b. Interpreting the gamma statistic in phylogenetic diversification rate studies: a rate decrease does not necessarily indicate an early burst. PLoS ONE, 5:e11781.

Fritz SA, Rahbek C, 2012. Global patterns of amphibian phylogenetic diversity. Journal of Biogeography, 39:1373-1382.

Gillespie RG, 2013. Adaptive radiation: convergence and nonequilibrium. Current Biology, 23:R71-R74.

Grenyer R, Orme CDL, Jackson SF, Thomas GH, Davies RG, Davies TJ, Jones KE, Olson VA, Ridgely RS, Rasmussen PC, Ding TS, Bennett PM, Blackburn TM, Gaston KJ, Gittleman JL, Owens IPF, 2006. Global distribution and conservation of rare and threatened vertebrates. Nature, 444:9396.

Harmon LJ, Losos JB, Jonathan Davies T, Gillespie RG, Gittleman JL, Bryan Jennings WB, Kozak KH, McPeek MA, Moreno-Roark F, Near TJ, Purvis A, Ricklefs RE, Schluter D, Schulte JA 2nd, Seehausen O, Sidlauskas BL, TorresCarvajal O, Weir JT, Mooers AØ, 2010. Early bursts of body size and shape evolution are rare in comparative data. Evolution, 64:2385-2396.

Harmon LJ, Weir JT, Brock CD, Glor RE, Challenger W, 2008. GEIGER: investigating evolutionary radiations. Bioinformatics, 24:129-131.

Jetz W, Thomas GH, Joy JB, Hartmann K, Mooers AO, 2012. The global diversity of birds in space and time. Nature, 491: 444-448.

Losos JB, 2010. Adaptive radiation, ecological opportunity, and evolutionary determinism. American Naturalist, 175:623639.

Myers EA, Burbrink FT, 2012. Ecological opportunity: trigger of adaptive radiation. Nature Education Knowledge, 3:23.

Paradis E, Claude J, Strimmer K, 2004. APE: analyses of phylogenetics and evolution in $\mathrm{R}$ language. Bioinformatics, 20: 289-290.

Phillimore AB, Price TD, 2008. Density-dependent cladogenesis in birds. PLoS Biology, 6:e71.

Pybus OG, Harvey PH, 2000. Testing macro-evolutionary models using incomplete molecular phylogenies. Proceedings of the Royal Society B: Biological Sciences, 267:2267-2272.

Pyron RA, Burbrink FT, 2012. Extinction, ecological opportunity, and the origins of global snake diversity. Evolution, 66: 163-178.

Pyron RA, Wiens JJ, 2011. A large-scale phylogeny of Amphibia including over 2800 species, and a revised classification of extant frogs, salamanders, and caecilians. Molecular Phylogenetics and Evolution, 61:543-583.

Qian H, 2009. Global comparisons of beta diversity among mammals, birds, reptiles and amphibians across spatial scales and taxonomic ranks. Journal of Systematics and Evolution, 47:509-514.

R Development Core Team, 2011. R: A Language and Environment for Statistical Computing [Internet]. R Foundation for Statistical Computing, Vienna, Accessed 1 Jan 2014, <http: //www.R-project.org>.

Rabosky DL, 2006. Likelihood methods for detecting temporal shifts in diversification rates. Evolution, 60:1152-1164.

Rabosky DL, 2007. LASER: a maximum likelihood toolkit for detecting temporal shifts in diversification rates from molecular phylogenies. Evolutionary Bioinformatics Online, 2: 273-276.

Rabosky DL, 2009. Ecological limits and diversification rate: alternative paradigms to explain the variation in species richness among clades and regions. Ecology Letters, 12:735743.

Rabosky DL, Donnellan SC, Talaba AL, Lovette IJ, 2007. Exceptional among-lineage variation in diversification rates during the radiation of Australia's most diverse vertebrate clade. Proceedings of the Royal Society B: Biological Sciences, 274:2915-2923.

Rabosky DL, Lovette IJ, 2008a. Density dependent diversification in North American wood warblers. Proceedings of the Royal Society B: Biological Sciences, 275:2363-2371.

Rabosky DL, Lovette IJ, 2008b. Explosive evolutionary radiations: decreasing speciation or increasing extinction through time? Evolution, 62:1866-1875.

Rabosky DL, Slater GJ, Alfaro ME, 2012. Clade age and species richness are decoupled across the eukaryotic tree of life. PLoS Biology, 10:e1001381.

Ricklefs RE, 2006. Global variation in the diversification rate of passerine birds. Ecology, 87:2468-2478.

Roelants K, Gower DJ, Wilkinson M, Loader SP, Biju SD, Guillaume K, Moriau L, Bossuyt F, 2007. Global patterns of diversification in the history of modern amphibians. Proceedings of the National Academy of Sciences of the United States of America, 104:887-892. 
Santini F, Harmon LJ, Carnevale G, Alfaro ME, 2009. Did genome duplication drive the origin of teleosts? A comparative study of diversification in ray-finned fishes. BMC Evolutionary Biology, 9:194.

Schluter D, 2000. The ecology of adaptive radiation. Oxford University Press, New York.

Wake DB, 1991. Declining amphibian populations. Science, 253, 860.

Wake DB, 2007. Climate change implicated in amphibian and lizard declines. Proceedings of the National Academy of Sciences of the United States of America, 104:8201-8202.

Wiens JJ, 2007. Global patterns of diversification and species richness in amphibians. American Naturalist, 170:S86-S106.
Wollenberg KC, Vieites DR, Glaw F, Vences M, 2011. Speciation in little: the role of range and body size in the diversification of Malagasy mantellid frogs. BMC Evolutionary Biology, 11:217.

Zimkus BM, Lawson L, Loader SP, Hanken J, 2012. Terrestrialization, miniaturization and rates of diversification in African Puddle frogs (Anura: Phrynobatrachidae). PLoS ONE, 7:e35118.

Received June 13, 2013 Revised October 28, 2013 Accepted November 2, 2013 